\section{Tongue abscess: a rare occurrence possibly mimicking angioedema}

\author{
Alessandro Riccardi, Paola Dignetti, \\ Franco Tasso, Matteo Caiti, Roberto Lerza \\ Emergency Department, San Paolo \\ Hospital, Savona, Italy
}

\begin{abstract}
Despite the popularity of tongue piercing in recent years, the finding of a tongue abscess is considered extremely rare by international literature. The few available reports refer to a situation generally well documented objectively, posing problems of differential diagnosis for cancer, metastases, cysts, foreign bodies, intraparenchymal hemorrhage, macroglossia and edema of various origins. An acute enlargement of the tongue can be difficult to diagnose especially if there are no mucosal breaks or inflammation, and it may obstruct the upper airway and be a clinical challenge. Here we report a case observed in our emergency department which, at presentation, seemed suggestive for an angioedema.
\end{abstract}

\section{Case Report}

A 51-year-old man was brought to our emergency department (ED) because, the night before his admission, he was showing dyslalia, dysphagia and tongue swelling, especially in the right half. His past history was inexpressive, and he did not report known allergies. He was not taking any drugs. The patient was afebrile, did not complain of any pain in his oral cavity, neither spontaneously nor to palpation of the tongue. There was no enlargement of submandibular and neck lymph nodes and the lingual mucosa did not show any alteration (Figure 1). All baseline blood tests were normal, except for a slight increase of C-reactive protein to $0.69 \mathrm{mg} / \mathrm{dL}$ (n.r. 0.05-0.3). In particular, the total and differential white blood cells counts were in the normal range. The consulted ear-nose-throat (ENT) professional noted slight edema on the right half of the tongue and on the floor of the mouth, and agreed with a provisional diagnosis of angioedema. Compared to the previous night the patient reported that his symptoms seemed to decrase, but nevertheless we gave $4 \mathrm{mg}$ betamethasone and $10 \mathrm{mg}$ clorphenamine parenterally. After a night under observation, the patient felt better and was discharged as his clinical picture seemed to have substantially improved. Two days later the patient returned to the ED, complaining of similar problems. This time his clinical picture was not particularly different from the previous one, except for a mild soreness of the tongue. The consulted ENT professional suggested again an angioedema since there were no changes in his lingual mucosa. This time, in addition to steroids and antihistamines, we administered Icatibant $1 \mathrm{f} 30 \mathrm{mg}$ subcutaneously and again we kept the patient under observation. The next morning he reported a partial improvement of his symptoms, however on the upper side of the tongue a small pustule had appeared. A large amount of pus came out after etching the pustule (Figure 2). The ultrasound test of the tongue revealed an abscess with a diameter of $17 \times 10 \times 15 \mathrm{~mm}$ located on the right side of the tongue body. Neck and chest tomography excluded the involvement of other structures. The patient was then transferred to a specialist unit for definitive treatment. He was discharged a few days later, in good health and asymptomatic. The bacterial culture of the pus was negative.

\section{Discussion}

This case was certainly not easy to diagnose and a misleading situation. In fact, if tongue abscess is considered a very rare event indeed, ${ }^{1-6}$ the same might be said for non-histaminergic angioedema, at least for those variants which are not related to angiotensinconverting enzyme inhibitors, as acquired or hereditary angioedema. ${ }^{7-10}$ Non-allergic angioedema is characteristically cold, without major urticaria or pruritic edema, and moreover in our patient signs of inflammation as pain, fever, leucocytosis, redness of the skin and mucosal membranes, lymph nodes enlargement were substantially absent. ${ }^{10}$ Then, on this basis, the diagnosis of acquired angioedema was possible, also given the lack of family history of similar episodes and the intake of specific drugs, in addition to the normal surface appearance of the lingual mucosa. No data led us to think of a tongue abscess. Also the oscillatory behaviour of the clinical picture was a confusing element, and probably had been caused by the anti-inflammatory effect of the administered steroids. The apparent response to therapy seemed consistent with the diagnostic hypothesis of angioedema. Moreover, the patient history was negative for possible injury by foreign body, trauma or tongue injuries. Without these elements, it is very difficult to think of a tongue abscess. In fact, the latter is a very rare occurrence, ${ }^{2,5}$ because the tongue is an organ generally resistant to infections thanks to its rich blood
Correspondence: Alessandro Riccardi, Emergency Department, San Paolo Hospital, via Genova 30, 17100 Savona, Italy.

Tel. +39.019 .8404963 - Fax: +39.019 .8404529 .

E-mail: a.riccardi@asl2.liguria.it

Key words: tongue, abscess, angioedema.

Contributions: the authors contributed equally.

Conflict of interests: the authors declare no potential conflict of interests

Received for publication: 15 February 2013.

Revision received: 29 August 2013.

Accepted for publication: 17 September 2013.

This work is licensed under a Creative Commons Attribution 3.0 License (by-nc 3.0).

(C) Copyright A. Riccardi et al., 2013

Licensee PAGEPress, Italy

Emergency Care Journal 2013; 9:e23

doi:10.4081/ecj.2013.e23

supply, thickness of the mucosa, its mainly muscular structure and the protective effect of saliva.

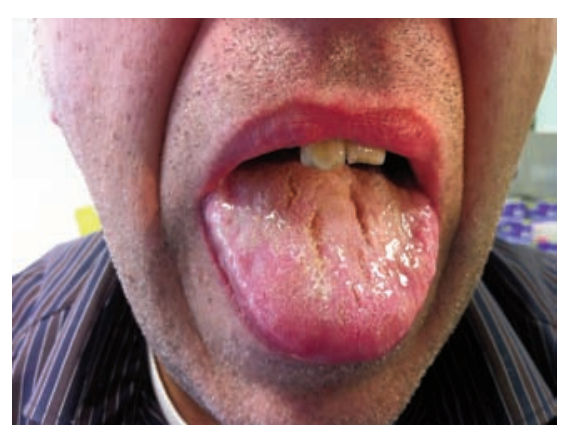

Figure 1. Swelling of the tongue without mucosal alterations.

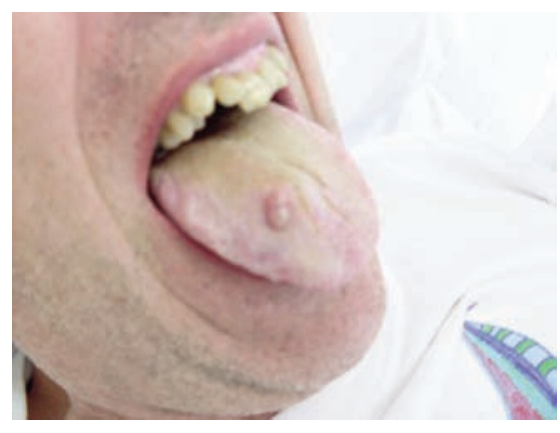

Figure 2. Drainage of pus from the lingual body. 


\section{Conclusions}

We believe that a poor oral hygiene and a compromised dentition may have been at least a contributing cause of the onset of this rare clinical picture. This is a potentially life-threatening infection especially if it extends to the posterior tongue area, and it is likely to determine an airway obstruction. Probably, also the risk of sepsis is not negligible. Therefore, the observation of patients is important, in order to record any changes in the clinical picture. This is also important for angioedema ${ }^{10}$ and, in our case, the observation allowed us to make the final diagnosis.

\section{References}

1. Olsen JC. Lingual abscess secondary to body piercing. J Emerg Med 2001;20:409.

2. Muñoz A, Ballesteros AI, Brandariz Castelo JA. Primary lingual abscess presenting as acute swelling of the tongue obstructing the upper airway: diagnosis with MR. Am J Neuroradiol 1998;19:496-8.

3. Mavili E, Oztürk M, Yücel T, et al. Tongue metastasis mimicking an abscess. Diagn Interv Radiol 2010;16:27-9.

4. Kim HJ, Lee BJ, Kim SJ, et al. Tongue abscess mimicking neoplasia. Am J Neuroradiol 2006;27:2202-3.

5. Byahatti SM, Ingafou MSH. Lingual abscess: a rarity. J Clin Exp Dent 2011; 3:e162-5.
6. Renehan A, Morton M. Acute enlargement of the tongue. Br J Oral Maxillofac Surg 1993;31:321-4.

7. Hoover T, Lippmann M, Grouzmann E, et al. Angiotensin converting enzyme inhibitor induced angio-oedema: a review of the pathophysiology and risk factors. Clin Exp Allergy 2010;40:50-61.

8. Cicardi M, Zanichelli A. Acquired angioedema. Ann Allerg Asthma Im 2010; 6:14.

9. Zuraw BL. Clinical practice. Hereditary angioedema. New Engl J Med 2008;359: 1027-36.

10. Riccardi A, Minuto P, Da Col A, et al. Onset of angioedema following a viper bite: different options for diagnostic procedure in an emergency department. Emerg Care J 2011;2:10-2. 